\title{
KONDISI SOSIAL EKONOMI NELAYAN PANCING TONDA DI DESA KAMPO- KAMPO KECAMATAN BINONGKO KABUPATEN WAKATOBI PROVINSI SULAWESI TENGGARA
}

\author{
Hendri'; Jeannette F. Pangemanan²; Vonne Lumenta² \\ 1)Mahasiswa Fakultas Perikanan dan IImu Kelautan Universitas Sam Ratulangi Manado \\ 2)Staff Pengajar Fakultas Perikanan dan IImu Kelautan Universitas Sam Ratulangi Manado \\ Koresponden email :hendrionechy@gmail.com
}

\begin{abstract}
The purpose of this research was to reveal and study the socio-economic condition of using Tonda fishing rods (100\%).

The research method used descriptive with the census basic. The analytical method used is quantitative and qualitative descriptive analysis.

In general, the education of the respondents was graduated from elementary and junior high school with a percentage of $30 \%$, most of the dependents family were 3 people. The condition of fisherman Tonda housing that is as much as $50 \%$ has permanent, $10 \%$ semi-permanent and $40 \%$ non-permanent.

The average production of each fishing Tonda fisherman is $684 \mathrm{~kg}$ per month. The income is IDR 102,600,000 per month, while other business income is IDR 5,300,000 with total revenue is IDR 107,900,000 per month. Expenditure is IDR 56,535,000 per month. The final income is IDR. 51,365,000 per month with the average is IDR. 5,136,500 each month.
\end{abstract}

Key words : Socio economic, trolling fisheries

\begin{abstract}
Abstrak
Tujuan penelitian ini adalah untuk mengungkapkan dan mengkaji kondisi sosial ekonomi nelayan yang menggunakan alat pancing Tonda di Desa Kampo-Kampo Kecamatan Binongko Kabupaten Wakatobi Provinsi Sulawesi Tenggara.

Metode penelitian yang digunakan, yaitu bersifat deskriptif dengan metode dasar sensus. Populasi dari penelitian ini adalah seluruh nelayan yang menggunakan alat pancing Tonda (100\%). Metode analisis yang digunakan adalah analisis deskriptif kuantitatif dan analisis deskriptif kualitatif.

Pada umumnya tingkat pendidikan responden adalah tamat SD dan SMP dengan persentase $30 \%$, sebagian besar tanggungan keluarga berjumlah 3 orang. Dari segi kesehatan hampir semua responden menggunakan sarana pengobatan, yaitu puskesmas pembantu. Keadaan perumahan nelayan pancing Tonda, yaitu sebanyak $50 \%$ memilki rumah permanen, rumah semi permanen $10 \%$ dan non permanen $40 \%$.

Produksi rata-rata setiap nelayan pancing Tonda $684 \mathrm{~kg} / \mathrm{bulan}$. Pemasaran hasil tangkapan langsung dijual ke konsumen oleh istri nelayan. Tetapi apabila ikan tidak habis terjual langsung memasarkannya ke desa setempat atau desa-desa tetangga. Pendapatan usaha perikanan pancing Tonda sebesar Rp. 102.600 .000 per bulan, sedangkan pendapatan usaha lainnya Rp. 5.300.000 dengan pendapatan total Rp. 107.900.000 per bulan. Pengeluaran nelayan pancing Tonda sebesar Rp. 56.535.000 per bulan. Pendapatan akhir nelaya pancing Tonda Rp. 51.365 .000 dengan rata-rata setiap nelayan Rp. 5.136 .500 per bulannya.
\end{abstract}

Kata kunci : Sosial ekonomi, perikanan tangkap

\section{PENDAHULUAN}

Kehidupan masyarakat nelayan adalah suatu keadaan nyata yang dapat diungkapkan melalui usaha mereka dan dipengaruhi oleh musim penangkapan ikan, kondisi alam, tingkat pendidikan yang masih rendah, penggunaan alat tangkap yang masih tradisional dan kendala ekonomi seperti terbatasnya modal sehingga usaha tidak dapat berkembang, serta transportasi yang tidak menunjangdan kelembagaan ekonomi yang tidak mendukung sehingga posisi nelayan dalam penentuan hasil tangkap dan pemasaran sangat kurang.

Kondisi seperti ini tidak lepas dari masalah-masalah pembangunan karena, dipengaruhi oleh berbagai aspek sosial ekonomi yang masih kurang dimengerti bahkan, ada yang tidak tahu sehingga sangat berpengaruh terhadap kehidupan masyarakat nelayan di pedesaan, 
sehubungan dengan ini maka pembangunan perikanan harus dilakukan dengan cara pendekatan sosial ekonomi.

Kabupaten Wakatobi Provinsi Sulawesi Tenggara terdiri dari empat pulau, yaitu pulau Wangi-Wangi, Kaledupa, Tomia dan Binongko. Pulau Binongko terdiri dari dua kecamatan, yaitu Kecamatan Binongko dan Kecamatan Togo Binongko, Desa Kampo-Kampo terletak di Kecamatan Binongkoyang merupakan lokasi penelitian. Para nelayan banyak menggunakan alat tangkap pancing Tonda, untuk itu perlu untuk mengetahui tentang kondisi sosial ekonominya.

\section{METODE PENELITIAN Metode Penelitian}

Jenis penelitian ini adalah deskriptif, penelitian bersifat deskriptif adalah penelitian yang bertujuan untuk mengungkapkan suatu kenyataan sosial dengan jalan mendeskripsikan secara tepat sifat-sifat individu, keadaan, gejala, kelompok tertentu berkenaan dengan masalah unit yang diteliti dalam masyarakat (Faisal, 2003). Metode dasar yang digunakan dalam penelitian ini adalah metode sensus.Pengertian sensus adalah cara pengumpulañ data apabila seluruh elemen populasi diselidiki satu per satu (Supranto, 2008), responden dijadikan sebagai objek penelitian itu sendiri.

\section{Metode Pengumpulan Data}

Pengumpulan data dilakukan melalui observasi. Observasi merupakan metode pengumpulan data yang dilakukan dengan cara mengamati dan mencatat secara sistematik gejala-gejala yang diselidiki (Supardi, 2006). Untuk melengkapi cara memperoleh data, penulis mempergunakan metode observasi nonpartisan, yaitu mengamati mencari data dari berbagai fakta yang ada hubungannya dengan permasalahan.

Populasi adalah seluruh nelayan yang menggunakan pancing Tonda, yaitu sebanyak 10 nelayan sebagai responden dari jumlah keseluruhan sebanyak 32 nelayan. Data yang dikumpulkan, yaitu data primer dan data sekunder. Data primer adalah data yang diperoleh melalui wawacara langsung, melalui pengisisan kuisioner dan juga alat perekam (Narimawati, 2008 ). Data sekunder merupakan data pendukung dari data primer yang diperoleh melalui dokumen dan data statistik serta instansi-instansi terkait, literatur-literatur dan bahan bacaan.

\section{Metode Analisis Data}

Analisis data hasil penelitian dibedakan dalam dua macam, yaitu analisis kuantitatif dan analisis kualitatif (Fathoni, 2006). Analisis kuantitatif merupakan pengolahan data dengan menggunakan perhitungan matematis sederhana seperti penjumlahan, pengurangan, perkalian, angka rata-rata, persentase (\%) dan sebagainya, yang meliputi analisis pendapatan dan pengeluaran secara sederhana, sumberdaya manusia, operasi/produksi dan pemasaran.Sedangkan analisis kualitatif adalah pengolahan data yang dilakukan melalui pertimbanganpertimbangan logika dengan bahasapenulis yang sistematis. Data yang telah dianalisis kemudian diinteRp. retasikan sebagai hasil penelitian, yang meliputi wawancara, analisis dokumen, diskusi, atau observasi pertimbanganpertimbangan logika dengan bahasabahasa penulis yang sistematis. 


\section{HASIL DAN PEMBAHASAN}

Keadaan Sosial Nelayan Pancing Tonda di Desa Kampo-kampo

\section{Pendidikan}

Tingkat pendidikan merupakan salah satu aspek sosial yang penting bagi nelayan, karena berpengaruh terhadap adopsi teknologi,tingkat pendidikan yang rendah akan sulit menerima teknologi baru.

Pendidikan juga merupakan salah satu faktor utama yang dapat membuka kesempatan kerja bagi nelayan yang hidup pas-pasan. Hasil penelitian terhadap tingkat pendidikan nelayan pancing Tonda di Desa Kampo-kampo dapat dilihat pada Gambar berikut.

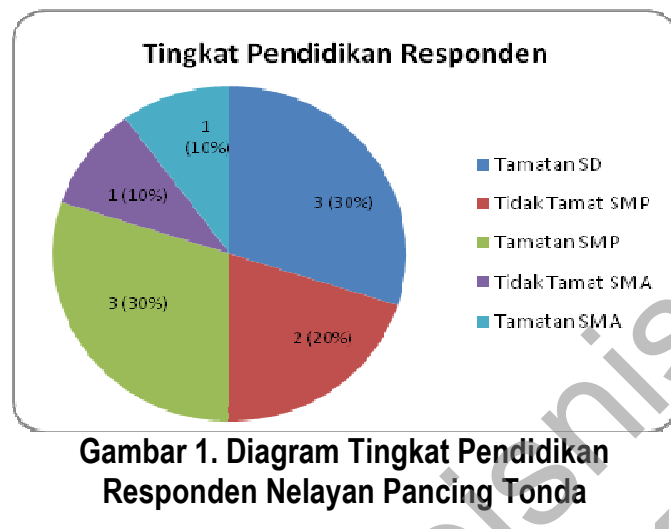

Gambar 1 menunjukkan diagram tingkat pendidikan responden, yaitu nelayan pancing Tonda. Pada diagram tersebut dapat dilihat bukti bahwa tingkat pendidikan responden yang terbanyak adalah tamatan SD dan SMP, karena sama-sama memiliki persentase $30 \%$ dari jumlah keseluruhan responden.

Rendahnya pendidikan, minimnya penyuluhan-penyuluhan dari pemerintah menyebabkan keterampilan dan pengetahuan mereka tentang perikanan sangat sedikit sehingga berpengaruh pada tingkat pendapatan yang mereka hasilkan. Nelayan hanya mendapat pengalaman dari orang tua secara turun temurun.

\section{Umur}

Umur merupakan salah satu faktor yang dapat memberikan gambaran tentang cara pandang seseorang. Terkadang semakin dewasa umur seseorang semakin bijak ia menyikapi atau merespon sesuatu. Berdasarkan umur penduduk yang berusia 0-14 tahun merupakan penduduk yang belum produktif, penduduk yang berusia 15-64 tahun merupakan penduduk dengan usia produktif, sedangkan penduduk yang berusia 65 tahun ke atas merupakan penduduk dengan usia kurang produktif (Kusumowidho, 2000). Hasil penelitian terhadap umur responden nelayan pancing Tonda dapat dilihat pada Gambar berikut.

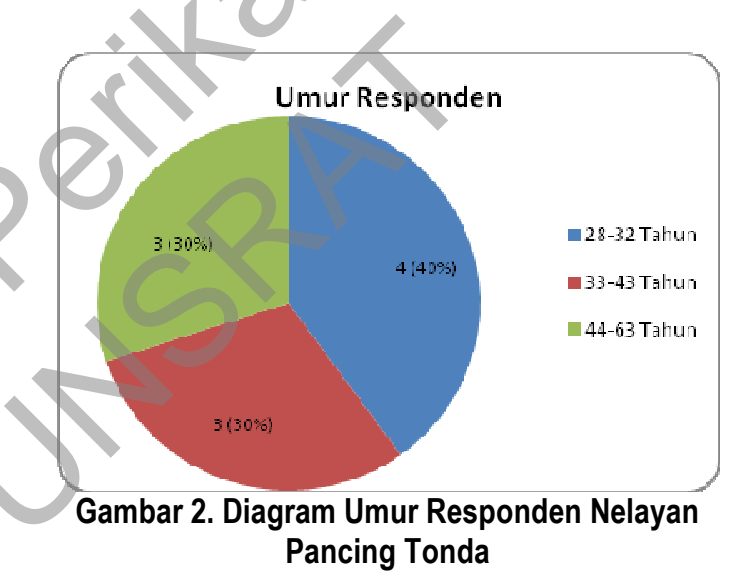

Gambar 2 menunjukkan diagram umur responden nelayan pancing Tonda, dapat dilihat bahwa umur 28-32 tahun merupakan jumlah terbanyak, karena $40 \%$ dari jumlah keseluruhan nelayan pancing Tonda berumur 28-32 tahun.

\section{Ukuran Keluarga}

Salah satu faktor yang penting mengenai keadaan sosial nelayan adalah ukuran keluarga, hal ini disebabkan karena semakin banyak jumlah anggota keluarga maka jumlah kebutuhan semakin banyak. Jumlah keluarga nelayan pancing Tonda dapat dilihat pada Gambar berikut ini. 


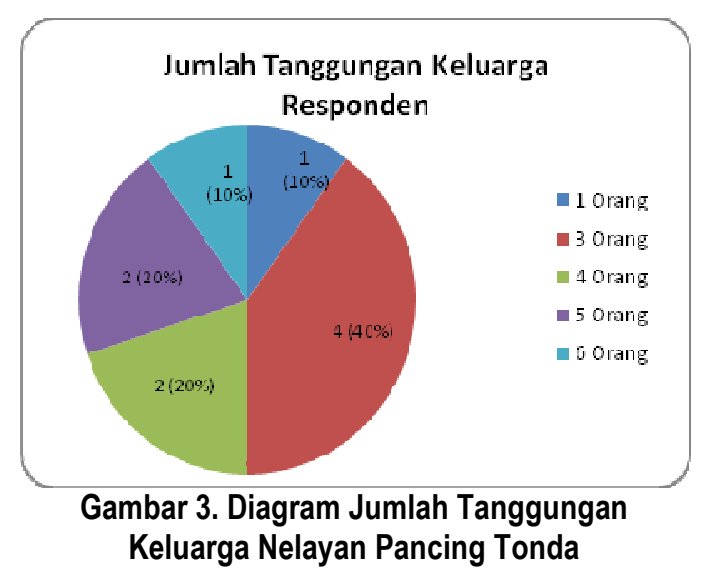

Gambar 3 menunjukkan jumlah ukuran keluarga nelayan pancing Tonda, dapat dilihat bahwa jumlah tanggungan terbanyak, yaitu 3 orang, karena memiliki persentase $40 \%$ dari jumlah keseluruhan ukuran keluarga nelayan pancing Tonda.

\section{Kesehatan}

Kesehatan merupakan salah satu indikator yang dipakai untuk menentukan kualitas hidup dan tingkat kesejahteraan keluarga.Hidup sehat merupakan keinginan dan harapan bagi setiap anggota masyarakat, apabila kesehatan seseorang terganggu maka aktifitas hidupnya akan ikut terganggu. Kesehatan setiap orang haruslah dijaga, karena kesehatan merupakan kunci utama dalam melakukan aktifitas pekerjaan. Deskripsi kesehatan dari setiap nelayan dapat dilihat pada Tabel 4.

Sebagian besar nelayan pancing Tonda berobat ke Puskesmas/Pustu sedangkan sisanya berobat secara tradisional.Penggunaan sarana pengobatan ini berhubungan dengan tingkat pendapatan, hal ini dipengaruhi oleh keberadaan sarana yang ada di Desa Kampo-kampo. Keikutsertaan nelayan dalam program $K B$, yaitu sebanyak 7 keluarga masing-masing menggunakan KB suntik, pil dan susuk. Sumber air berasal dari PDAM dan air sumur yang digunakan untuk keperluan memasak, minum dan lain-lain.

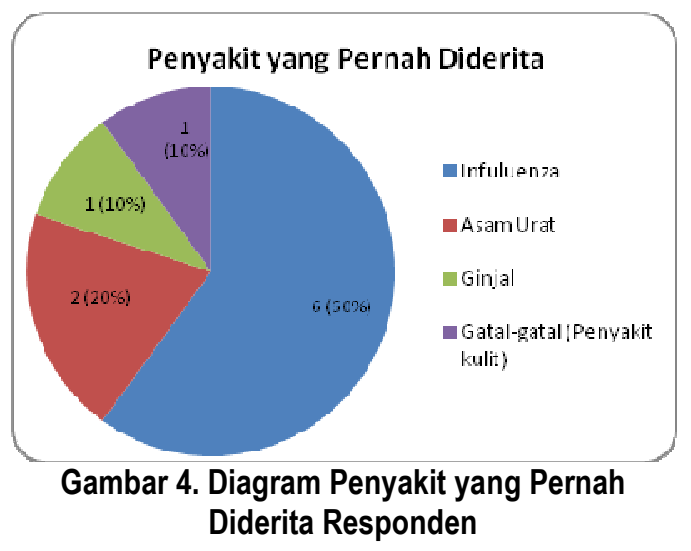

Gambar 4 menunjukkan penyakit yang pernah diderita responden, yaitu penyakit infuluensa merupakan jenis penyakit terbanyak, karena memiliki persentase $60 \%$,

\section{Perumahan}

Perumahan merupakan salah satu kebutuhan pokok masyarakat yang harus dipenuhi, juga sebagai alat ukur untuk taraf hidup seseorang. Rumah bagi nelayan pancing Tonda adalah sebagai tempat tinggal dan tempat bernaung.Untuk lebih jelasnya, jenis perumahan yang dimiliki nelayan di Desa Kampo-kampo dapat dilihat pada Gambar berikut.

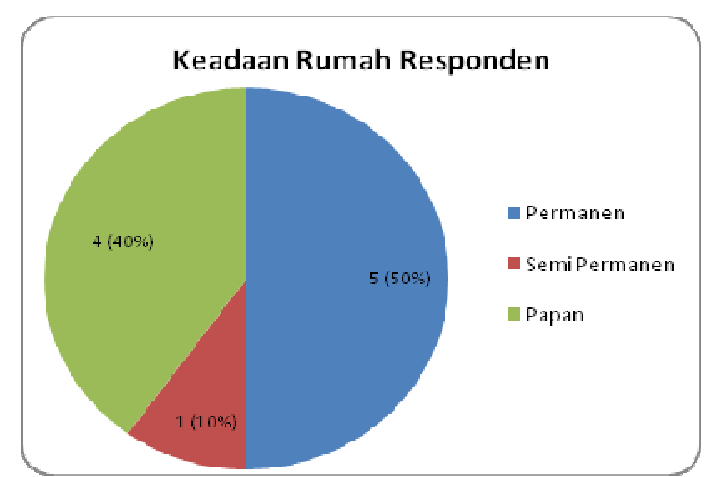

Gambar 5. Diagram Keadaan Rumah Responden

Gambar 5 memperlihatkan keadaan rumah responden yang paling banyak, yaitu rumah permanen memiliki persentase $50 \%$, sedangkan $10 \%$ adalah rumah non permanen. Hal ini membuktikan bahwa rumah papan 
merupakan keadaan rumah responden yang paling terkecil atau paling sedikit.

\section{Keadaan Ekonomi Nelayan Pancing Tonda di Desa Kampo-kampo Modal Usaha}

Modal memiliki peranan yang sangat penting dalam setiap usaha dalam meningkatkan dan mengembangkan usaha agar supaya dapat lebih maju dan berhasil. Tanpa ada modal maka tidak mungkin suatu usaha akan berjalan denga baik.

Nelayan responden ada yang memiliki modal sendiri/pribadi dan ada yang berasal dari pinjaman, dapat dilihat pada Tabel berikut ini.

Tabel 1. Modal Usaha Setiap Nelayan Pancing Tonda

\begin{tabular}{|c|l|c|c|}
\hline No. & \multicolumn{1}{|c|}{ Nama } & $\begin{array}{c}\text { Jumlah Modal } \\
\text { (Rp.) }\end{array}$ & Keterangan \\
\hline 1. & Alimudin & 35.000 .000 & Modal Sendiri \\
\hline 2. & Gustiawan & 15.000 .000 & Modal Sendiri \\
\hline 3. & Hasanudin. B & 10.000 .000 & Modal Sendiri \\
\hline 4. & Hasludin & 15.000 .000 & Modal Sendiri \\
\hline 5. & Kasman & 11.000 .000 & Modal Sendiri \\
\hline 6. & La Toni & 17.000 .000 & Modal Pinjaman \\
\hline 7. & La Aliara & 7.000 .000 & Modal Sendiri \\
\hline 8. & Madiliha & 25.000 .000 & Modal Sendiri \\
\hline 9. & Saliadi & 16.000 .000 & Modal Sendiri \\
\hline 10 & Samiludin Jumlah & 5.000 .000 & Modal Sendiri \\
\hline & Rata-rata & 173.000 .000 & \\
\hline & 17.300 .000 & \\
\hline
\end{tabular}

Sumber : Data Primer 2018

Tabel 1 menunjukkan bahwa usaha mereka memerlukan modal yang besar. Modal ini disesuaikan dengan kebutuhan perlengkapan untuk melakukan usaha penangkapan íkan. Tinggi rendahnya jumlah modal usaha responden tergantung pada alat penangkapan yang dioperasikan seperti perahu, jumlah dan jenis mesin berbedabeda.Hanya seorang responden yang memiliki modal pinjaman, yang berasal dari sanak keluarga dengan bunga sebesar $25 \%$ perbulannya dan baru dapat dilunasi selama 3 (tiga) tahun.

\section{Produksi}

Hasil tangkapan nelayan pancing Tonda umumnya jenis tuna dan cakalang, dan dalam sekali melaut jumlah hasil tangkapan berbeda-beda, karena faktor cuaca. Biasanya jika hasil tangkapan banyak rata-rata memperoleh $60 \mathrm{~kg}$, bahkan lebih, akan tetapi jika hasil tangkapan sedikit rata-rata hanya memperoleh $20 \mathrm{~kg}$ kadangkala tidak ada sama sekali, dapat dilihat pada Tabel 2.

Tabel 2. Produksi Ikan Nelayan Pancing Tonda

\begin{tabular}{|c|c|c|c|c|c|c|}
\hline \multirow{2}{*}{ No. } & \multirow{2}{*}{ Nama } & Minggu 1 & Minggu 2 & Minggu 3 & Minggu 4 & Jumlah \\
\hline & & \multicolumn{5}{|c|}{ 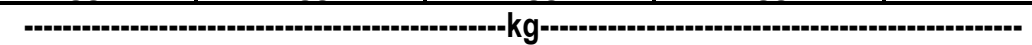 } \\
\hline 1. & Alimudin & 200 & 250 & 150 & 200 & 800 \\
\hline 2. & Gustiawan & 170 & 150 & 180 & 140 & 640 \\
\hline 3. & Hasanudin. B & 150 & 200 & 230 & 220 & 800 \\
\hline 4. & Hasludin & 120 & 180 & 190 & 110 & 600 \\
\hline 5. & Kasman & 210 & 170 & 230 & 190 & 800 \\
\hline
\end{tabular}




\begin{tabular}{|c|c|c|c|c|c|c|}
\hline \multirow{2}{*}{ No. } & \multirow{2}{*}{ Nama } & Minggu 1 & Minggu 2 & Minggu 3 & Minggu 4 & Jumlah \\
\hline & & \multicolumn{5}{|c|}{ - } \\
\hline 6. & La Toni & 180 & 190 & 110 & 120 & 600 \\
\hline 7. & La Aliara & 110 & 120 & 200 & $\overline{170}$ & 600 \\
\hline 8. & Madiliha & 120 & 130 & 130 & 120 & 500 \\
\hline 9. & Saliadi & 190 & 180 & 200 & 130 & 700 \\
\hline 10. & Samiludin & 190 & 200 & 240 & 170 & 800 \\
\hline & Jumlah & 1640 & 1770 & 1860 & 1570 & 6840 \\
\hline & Rata-rata & 164 & 177 & 186 & 157 & 684 \\
\hline
\end{tabular}

Sumber :Data Primer Selama Bulan Mei 2018

Tabel 2 menunjukkan bahwa hasil produksi ikan nelayan pancing Tonda di Desa Kampo-kampo secara keseluruhan sebanyak $6.840 \mathrm{~kg}$ dengan rata-rata setiap nelayan $684 \mathrm{~kg}$ selama bulan Mei 2018. Dari hasil wawancara selama penelitian ternyata puncak musim ikan, yaitu pada musim Timur berlaku pada bulan Mei sampai dengan bulan September, namun untuk produksi ikan paling banyak hanya tiga bulan saja mulai dari bulan Juni sampai dengan September.

\section{Pemasaran}

Peningkatan produksi pada usaha perikanan sangat ditentukan oleh keberhasilan dalam pemasaran, setiap hasil tangkapan memerlukan distribusi secara lancar mulai dari produsen hingga konsumen.

Biasanya para istri nelayan selalu menjemput para nelayan di pesisir pantai untuk memasarkan dan menentukan harga ikan sebesar Rp. 20.000/kg apabila musim tangkapannya sedikit, sedangkan pada musim tangkapan banyak harganya $\mathrm{Rp}$. $10.000 / \mathrm{kg}$.

Aktivitas ini sudah menjadi kebiasaan para istri nelayan, dikarenakan para konsumen yang datang langsung ke pesisir pantai tempat pendaratan perahu, bahkan para konsumen rumah tangga yang berasal dari Desa Kampo-kampo maupun desadesa tetangga lain, yaitu Desa One-one, Keluran Rukuwa dan Kelurahan Palahidu sering berebut hasil tangkapan bila cuaca sedang buruk. Jika cuaca perairan baik, maka hasil produksi ikan melimpah dan hasilnya pada masyarakat desa setempat dan desadesa tetangga lainnya sebagai konsumen rumah tangga.

\section{Tingkat Pendapatan}

Berdasarkan hasil penelitian, tingkat pendapatan nelayan pancing Tonda yang berada di Desa kampokampo bervariasi, sesuai aktivitas masing-masing nelayan tergantung seberapa sering memancing dalam sebulan.Pendapatan nelayan pancing Tonda dihitung berdasarkan penghasilan utama, yaitu sebagai nelayan kemudian dari penghasilan sampingan, yaitu berasal dari usaha tani, usaha rompong dan bisnis pakaian.

Perhitungan pendapatan dari nelayan diperoleh dari besarnya produksi dikalikan dengan harga jual ikan kemudian dijumlahkan. Tingkat pendapatan nelayan pancing Tonda dapat dilihat pada Tabel berikut. 
Tabel 3. Tingkat Pendapatan Nelayan Pancing Tonda per Bulan

\begin{tabular}{|c|c|c|c|c|c|}
\hline \multirow[b]{2}{*}{ No. } & \multirow[b]{2}{*}{ Nama } & \multirow[b]{2}{*}{ Pekerjaan Sampingan } & \multicolumn{2}{|c|}{ Pendapatan } & \multirow[b]{2}{*}{ Jumlah (Rp. ) } \\
\hline & & & Sampingan (Rp. ) & $\begin{array}{c}\text { Nelayan } \\
\text { Pancing Tonda (Rp.) }\end{array}$ & \\
\hline 1. & Alimudin & Usaha rompong & 3.000 .000 & 12.000 .000 & 15.000 .000 \\
\hline 2. & Gustiawan & - & - & 9.600 .000 & 9.600 .000 \\
\hline 3. & Hasanudin. B & - & - & 12.000 .000 & 12.000 .000 \\
\hline 4. & Hasludin & - & - & 9.000 .000 & 9.000 .000 \\
\hline 5. & Kasman & - & - & 12.000 .000 & 12.000 .000 \\
\hline 6. & La Toni & - & - & 9.000 .000 & 9.000 .000 \\
\hline 7. & La Aliara & - & - & 9.000 .000 & 9.000 .000 \\
\hline 8. & Madiliha & Tani & 300.000 & 7.500 .000 & 7.800 .000 \\
\hline 9. & Saliadi & - & - & 10.500 .000 & 10.500 .000 \\
\hline 10. & Samiludin & Bisnis pakaian & 2.000 .00 & 12.000 .000 & 14.000 .000 \\
\hline \multicolumn{3}{|c|}{ Jumlah } & 5.300 .000 & 102.600 .000 & 107.900 .000 \\
\hline \multicolumn{3}{|c|}{ Rata-rata } & 530.000 & 10.260 .000 & 10.790 .000 \\
\hline
\end{tabular}

Sumber : Data Primer, 2018

Jumlah keselurahan pendapatan nelayan pancing Tonda ditambah dengan penghasilan tambahan perbulan tergolong besar untuk kelompok masyarakat nelayan, yakni Rp. 142.100.000 dengan jumlah rata-rata per keluargaRp. 14.210.000, akan tetapi jumlah tersebut belum termasuk pengeluaran biaya keseluruhan.

\section{Tingkat Pengeluaran}

Biaya kebutuhan sehari-hari setiap keluarga nelayan termasuk makanan, pakaian, pendidikan, kesehatan dan lainya, disesuaikan dengan jumlah anggota keluarga, karena kemampuan suatu rumah tangga untuk membeli bahan makanan dipengaruhi oleh pendapatan yang dibatasi dengan jumlah anggota keluarga, semakin besar jumlah keluarga maka semakin tinggi, demikian juga sebaliknya.

Tabel 3. Tingkat Pengeluaran Nelayan Pancing Tonda per Bulan

\begin{tabular}{|c|c|c|c|c|c|c|}
\hline No. & Makanan (Rp. ) & Pendidikan (Rp. ) & Pakaian (Rp. & $\begin{array}{l}\text { Kesehatan (Rp. } \\
\text { ) }\end{array}$ & Lain-lain (Rp. ) & Jumlah (Rp. ) \\
\hline 1. & 1.000 .000 & 2.000 .000 & 100.000 & 50.000 & 4.000 .000 & 7.150 .000 \\
\hline 2. & 500.000 & -1 & 80.000 & 50.000 & 3.500 .000 & 4.130 .000 \\
\hline 3. & 1.000 .000 & 600.000 & 80.000 & 50.000 & 4.000 .000 & 5.730 .000 \\
\hline 4. & 500.000 & $\sqrt{-1}$ & 60.000 & 10.000 & 4.500 .000 & 5.070 .000 \\
\hline 5. & 750.000 & - & 125.000 & 50.000 & 5.000 .000 & 5.925 .000 \\
\hline 6. & 1.000 .000 & 50.000 & 150.000 & 20.000 & 6.000 .000 & 7.220 .000 \\
\hline 7. & 750.000 & 600.000 & 80.000 & 50.000 & 3.500 .000 & 4.980 .000 \\
\hline 8. & 700.000 & 300.000 & 20.000 & 50.000 & 3.500 .000 & 4.570 .000 \\
\hline 9. & 1.000 .000 & 300.000 & 10.000 & 50.000 & 4.500 .000 & 5.860 .000 \\
\hline 10. & 500.000 & 700.000 & 50.000 & 150.000 & 4.500 .000 & 5.900 .000 \\
\hline Total & 7.700 .000 & 4.550 .000 & 755.000 & 530.000 & 43.000 .000 & 56.535 .000 \\
\hline $\begin{array}{l}\text { Rata- } \\
\text { rata }\end{array}$ & 770.000 & 650.000 & 75.500 & 53.000 & 4.300 .000 & 5.653 .500 \\
\hline
\end{tabular}

Sumber : Data Primer, 2018

Tingkat pengeluaran nelayan pancing Tonda di Desa Kampo-kampo totalnya adalah Rp. 56.535 .000 per bulan, dengan jumlah pengeluaran rata- rata setiap keluarga Rp. 5.653 .500 per bulan.

Jenis pengeluaran yang paling besar adalah lain-lain yakni Rp. 43.000.000 dengan jumlah rata-rata 
setiap keluarga Rp. 4.300 .000 per bulannya, pengeluaran lain-lain seperti biaya listrik, perlengkapan rumah tangga dan sebagainya. Jenis pengeluaran yang paling sedikit adalah kesehatan yakni Rp. 530.000,, yaitu jumlah pengeluaran rata-rata setiap keluarga
Rp. 53.000 hal ini dikarenakan nelayan dan para anggota keluarganya hampir tidak pernah diserang penyakit, karena kebiasaan masyarakat nelayan ada yang masih melakukan pengobatan secara tradisional.

Tabel 4. Pendapatan Akhir Nelayan Pancing Tonda per Bulan

\begin{tabular}{|c|l|c|c|c|}
\hline No. & \multicolumn{1}{|c|}{ Nama } & Pendapatan (Rp.) & Pengeluaran (Rp.) & Pendapatan Akhir (Rp.) \\
\hline 1. & Alimudin & 15.000 .000 & 7.150 .000 & 7.850 .000 \\
\hline 2. & Gustiawan & 9.600 .000 & 4.130 .000 & 5.470 .000 \\
\hline 3. & Hasanudin. B & 12.000 .000 & 5.730 .000 & 6.270 .000 \\
\hline 4. & Hasludin & 9.000 .000 & 5.070 .000 & 3.930 .000 \\
\hline 5. & Kasman & 12.000 .000 & 5.925 .000 & 6.075 .000 \\
\hline 6. & La Toni & 9.000 .000 & 7.220 .000 & 1.780 .000 \\
\hline 7. & La Aliara & 9.000 .000 & 4.980 .000 & 4.020 .000 \\
\hline 8. & Madiliha & 7.800 .000 & 4.570 .000 & 3.230 .000 \\
\hline 9. & Saliadi & 10.500 .000 & 5.860 .000 & 4.640 .000 \\
\hline 10. & Samiludin & 14.000 .000 & 5.900 .000 & 8.100 .000 \\
\hline \multicolumn{2}{|c|}{ Total } & $\mathbf{1 0 7 . 9 0 0 . 0 0 0}$ & $\mathbf{5 6 . 5 3 5 . 0 0 0}$ & $\mathbf{5 1 . 3 6 5 . 0 0 0}$ \\
\hline \multicolumn{2}{|c|}{ Rata-rata } & $\mathbf{1 0 . 7 9 0 . 0 0 0}$ & $\mathbf{5 . 6 5 3 . 5 0 0}$ & $\mathbf{5 . 1 3 6 . 5 0 0}$ \\
\hline
\end{tabular}

Sumber : Data Primer, 2018

Pendapatan akhir, yaitu pandapatan rata-rata perkeluarga dikurangi dengan jumlah rata-rata pengeluaran selama sebulan maka hasilnya Rp. 10.790 .000 - Rp. $5.653 .500=$ Rp. 5.790 .000 .

Berdasarkan jumlah pendapatan akhir maka dapat disimpulkan bahwa besarnya pendapatan nelayan dapat menutupi biaya-biaya pengeluaran. Pendapatan keluarga nelayan biasanya ditabung dan disimpan di Bank, maupun ikut arisan kelompok masyarakat, karena pendapatan akhir ini hanya pada waktu musim penangkapan sekitar lima bulan saja, yaitu dari bulan Mei hingga bulan September. Akan tetapi masih ada beberapa nelayan yang sering menghabiskan uang dengan berpesta pora, mabuk-mabukkan dan lain sebagainya. Mereka berpendapat apa yang diperoleh hari ini untuk hari ini, sedangkan hari esok nanti menangkap ikan lagi dan begitu seterusnya.

Ungkapan seperti ini dikarenakan tingkat pendidikan yang rendah, berada pada lingkungan pertemanan nelayan yang menjadikan hal ini sebagai tradisi mereka.Pendekatan yang diarahkan pada perubahan sikap, mental dan tingkah laku melalui kegiatan penyuluhan tentang pola hidup sederhana dan sehat perlu untuk di sosialisasikan.

\section{KESIMPULAN}

\section{Kesimpulan}

Berdasarkan hasil pembahasan maka dapat ditarik kesimpulan sebagai berikut:

1. Pada umumnya tingkat pendidikan responden adalah tamat SD dan SMP sama-sama memiliki presentase $30 \%$, $20 \%$ tidak tamat SMP dan 10\% tamat SMA, $10 \%$ nya lagi tidak tamat SMA.

2. Dari segi kesehatan hampir semua responden menggunakan sarana pengobatan di puskesmas pembantu sedangkan yang lain berobat secara tradisional.

3. Keadaan perumahan nelayan pancing Tonda, yaitu sebanyak $50 \%$ memilki 
rumah permanen, rumah semi permanen $10 \%$ dan non permanen $40 \%$.

4. Usaha nelayan pancing Tonda dengan modal yang digunakan ratarata modal sendiri hanya seorang nelayan yang menggunakan modal pinjaman. Pencapaian produksi ratarata setiap nelayan pancing Tonda $684 \mathrm{~kg} / \mathrm{bulan}$. Pemasaran hasil tangkapan langsung dijual ke konsumen oleh istri nelayan pada saat mendarat di pesisir pantai tetapi ketika tidak habis terjual sang istri langsung memasarkannya ke desa setempat atau desa-desa tetangga.

5. Pendapatan usaha perikanan pancing Tonda besarnya Rp. 102.600.000per bulan, sedangkan pendapatan usaha lainnya Rp. 5.300 .000 dengan pendapatan total Rp. 107.900.000 per bulan.

6. Pengeluaran nelayan pancing Tonda sebesar Rp. 56.535 .000 per bulan. Pendapatan akhir nelayan pancing Tonda Rp. 51.365.000 dengan ratarata setiap nelayan Rp. 5.136.500 per bulannya, sesuai dengan tanggungan keluarga sebanyak 3 orang.

7. Jumlah pendapatan yang diperoleh setiap nelayan pancing Tonda dapat menutupi biaya-biaya pengeluaran. Pendapatan keluarga nelayan biasanya ditabung, maupun ikut arisan kelompok masyarakat.

\section{Saran}

1. Mengingat usaha nelayan pancing Tonda semakin berkembang, akan tetapi kemampuan manajemen para nelayan masih rendah diharapkan perhatian pemerintah setempat dapat membentuk koperasi sehingga mendorong nelayan untuk lebih maju dalam berusaha.

2. Diharapkan keterlibatan pemerintah dalam hal ini Dinas Perikanan untuk me berikan pendidikan non formal, yaitu penyuluhan, mengingat pendidikan formal yang mereka peroleh masih rendah agar produktivitas mereka dapat lebih ditingkatkan.

\section{DAFTAR PUSTAKA}

Faisal, S. 2003. Dasar-Dasar Manajemen Keuangan. Edisi Pertama. Malang : Universitas Muhammadiyah.

Fathoni, A. 2006.Metodologi Penelitian dan Teknik Penyusunan Skripsi. Jakarta: PT. Rineka Cipta.

Kusumowidho. 2000. Dasar-dasar Demografi. Lembaga Demografi Fakultas Ekonomi Universitas Indonesia, Jakarta.

Supardi, M.D. 2006.Metodologi Penelitian. Mataram: Yayasan Cerdas Press.

Supranto, J. 2008. Statistik : Teori dan Aplikasi. Edisi Ke-7 Jilid 1. Jakarta: Erlangga.

Umi Narimawati, 2008. Metodologi Penelitian Kualitatif dan Kuantitatif, Teori dan Aplikasi. Bandung: Agung Media. 
PS. Agrobisnis Perikanan FPIK UNSRAT

AKULTURASI

Available online :http://ejournal.unsrat.ac.id/index.php/akulturasi

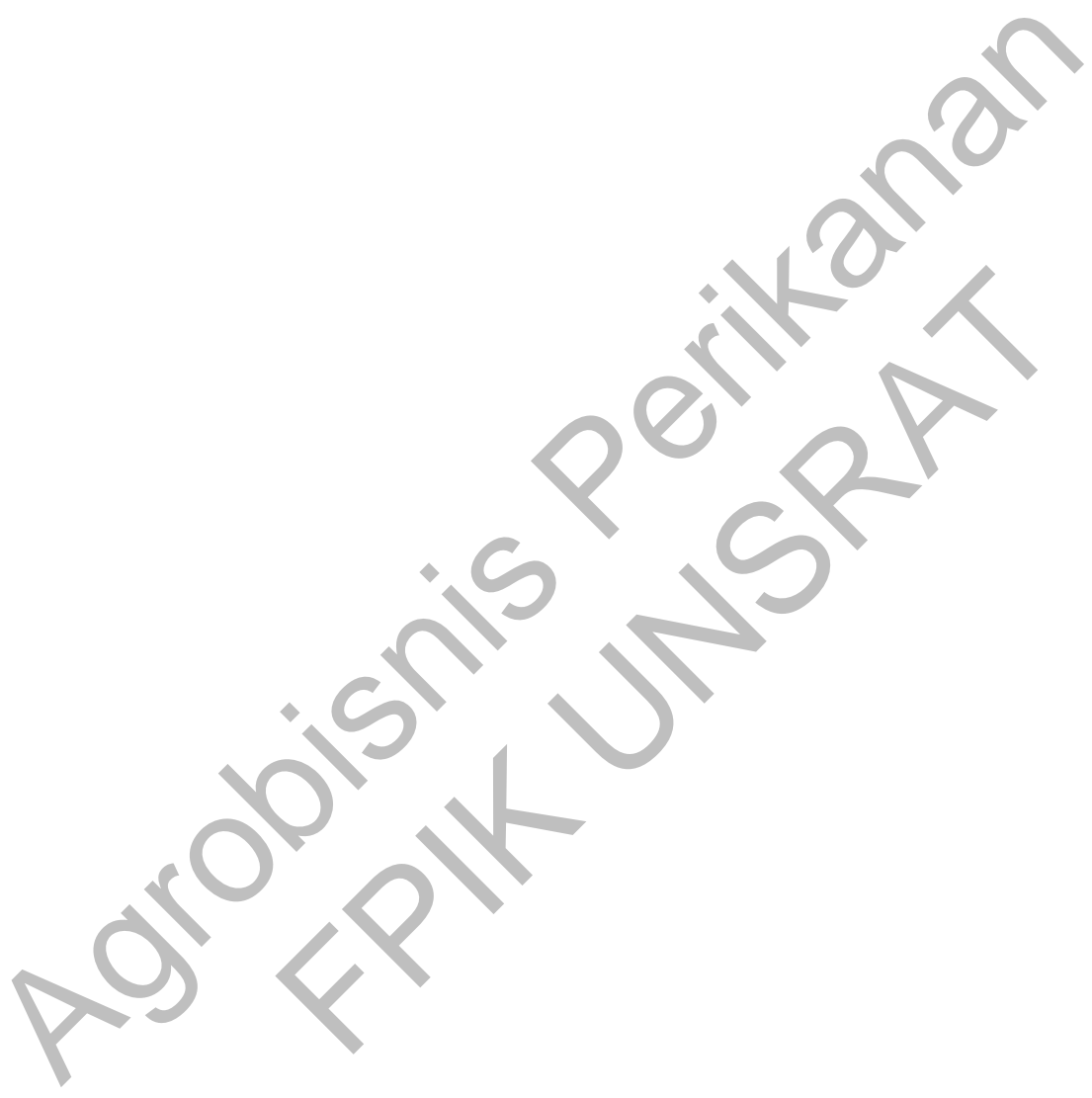

